\title{
Distribuição espaço-temporal da leptospirose e fatores de risco em Belém, Pará, Brasil
}

\author{
Leptospirosis space-time distribution and risk factors \\ in Belém, Pará, Brazil
}

Nelson Veiga Gonçalves ${ }^{1}$

Ediane Nunes de Araujo ${ }^{2}$

Alcinês da Silva Sousa Júnior ${ }^{3}$

Waltair Maria Martins Pereira ${ }^{4}$

Claudia do Socorro Carvalho Miranda ${ }^{5}$

Pedro Silvestre da Silvia Campos ${ }^{1}$

Mauro Wendel de Souza Matos ${ }^{1}$

Vera Regina da Cunha Menezes Palácios ${ }^{6}$

${ }^{1}$ Instituto Ciberespacial,

Universidade Federal Rural da Amazônia. Av. Pres.

Tancredo Neves 2501,

Montese. 66077-530 Belém

PA Brasil.nelsoncg2009@

gmail.com

${ }^{2}$ Santa Casa de Misericórdia

do Pará. Belém PA Brasil.

${ }^{3}$ Laboratório de

Epidemiologia e

Geoprocessamento,

Universidade do Estado do

Pará (UEPA). Belém PA

Brasil.

${ }^{4}$ Faculdade de Medicina, Universidade Federal do

Pará. Belém PA Brasil.

${ }^{5}$ Secretaria de Educação do

Estado do Pará, Governo do

Estado do Pará. Belém PA

Brasil.

${ }^{6}$ Faculdade de Medicina,

UEPA. Belém PA Brasil.
Abstract The occurrence of leptospirosis has defied epidemiology even when using different analysis technologies at local geographical levels. This cross-sectional and descriptive study sought to identify spatial correlations between social and environmental risk factors and leptospirosis in Belém in the State of Pará from 2007 to 2013. Epidemiological data were obtained from the Information System for Notifiable Diseases of the Pará State Department of Public Health and the environmental, demographic and cartographical data from the Brazilian Institute of Geography and Statistics. Men aged 20 to 39 of unknown profession and mixed ethnicity were the most affected. Laboratory diagnosis (82\%) and hospital care $(67.22 \%)$ confirmed satisfactory access to the Unified Health System. Numerical Kriging indicated the highest concentrations of the disease in the Guamá and Jurunas neighborhoods in lower lying areas near canals. The Buffer technique showed higher concentrations of the disease in areas with no domestic solid garbage collection service (26\%), sewage (22\%), piped water (38\%), with unpaved roads (20\%) and street flooding (65\%). The Moran technique revealed a direct spatial correlation between these variables ( $p=$ 0.01543). The general trend showed the decrease of the disease.

Key words Leptospirosis, Epidemiology, Medical geography
Resumo A ocorrência da leptospirose tem desafiado a epidemiologia na utilização de diferentes tecnologias de análises em escalas geográficas locais. Este estudo transversal e descritivo objetivou identificar correlações espaciais de fatores de risco socioambientais com a leptospirose em Belém, Pará, entre 2007 e 2013. Os dados epidemiológicos foram obtidos no Sistema de Informação de Agravos de Notificação, da Secretaria do Estado de Saúde Pública e os ambientais, demográficose territoriais no Instituto Brasileiro de Geografia e Estatística. Homens, 20 a 39 anos, ocupação indeterminada, etnia parda, foram os mais acometidos. O diagnóstico laboratorial (82\%) e o atendimento hospitalar $(67,22 \%)$ demonstraram acesso satisfatório ao Sistema de Saúde. A Krigagem numérica mostrou a maior concentração da doença nos bairros Guamá e Jurunas, em áreas de menores cotas altimétricas, próximas a canais. A técnica de Buffer apontou maior concentração da doença em áreas de ausência de coleta de resíduos sólidos domiciliares (26\%), esgoto (22\%), água encanada (38\%), e com arruamento não pavimentado (20\%) e alagamento de rua (65\%). A técnica de Moran demonstrou uma correlação espacial direta entre estas variáveis ( $p=0,01543)$. A tendência geral expressou o decréscimo da doença.

Palavras-chave Leptospirose, Epidemiologia, Geografia Médica 


\section{Introdução}

A leptospirose é uma doença secular de importância mundial que acomete animais e humanos, podendo produzir infecção grave. Animais silvestres e domésticos servem de reservatório. Em área urbana, os roedores sinantrópicos são os principais reservatórios, cães e animais de produção também são considerados reservatórios importantes. O homem é considerado hospedeiro acidental e terminal dentro da cadeia de transmissão ${ }^{1,2}$.

A fase inicial leptospirêmica é caracterizada por febre, cefaleia, mialgia, anorexia, náuseas e vômitos, presentes em $90 \%$ dos casos, semelhante a outras doenças febris agudas. Essa fase tende a evolução espontânea de três a sete dias sem deixar sequelas. Em aproximadamente 15\% dos casos, a leptospirose progride para a fase tardia da doença, que é associada a manifestações graves e potencialmente letais ${ }^{2,3}$.

No Brasil, a leptospirose é uma doença endêmica, com uma média de 13.000 casos notificados por ano, sendo 3.500 confirmados, com letalidade média de 10,8\%. Surtos epidêmicos aparecem associados com questões ambientais tais como períodos chuvosos, com ocorrência de enchentes e inundações ${ }^{4}$. Atinge em sua maioria o sexo masculino, moradores de zona urbana e periurbana, com baixa escolaridade e na faixa etária economicamente ativa ${ }^{5}$.

A média de internações de pacientes chega a $75 \%$, mostrando a gravidade da maioria dos casos detectados pelo sistema de vigilância epidemiológica. Esta doença tem elevado custo social em termos de anos potenciais de vida perdidos e gasto hospitalar ${ }^{2,6,7}$.

A cidade de Belém apresenta em sua área urbana grandes extensões com cotas altimétricas abaixo de 4 metros, que sofrem influência das marés altas e apresentam dificuldade para escoamento das águas pluviais. Estas áreas são chamadas “baixadas de Belém”. O rio Guamá, as bacias do rio Guajará e do Marajó são acidentes geográficos importantes na sua conformação. O clima é quente e úmido com precipitação média anual alcançando os $2.834 \mathrm{~mm}$, sendo que estas características têm sido alteradas, nas últimas décadas, pela ocorrência de eventos climáticos, dentre estes o El Niño e o La Niña. A temperatura média é de $25^{\circ} \mathrm{C}$ em fevereiro e $26^{\circ} \mathrm{C}$ em novembro, com ausência de estação fria, condições ideais para que o patógeno permaneça infectante quando suspenso em meio hídrico, por uma média de até seis meses ${ }^{7-16}$.
A cidade de Belém possui Índice de Desenvolvimento Humano Municipal (IDHM) de 0,746, taxa de alfabetização de $94,82 \%$, renda per capita do município de $\mathrm{R} \$ 853,82$ reais e taxa de pobreza da população de $18,2 \%$, assim sendo, a utilização de variáveis socioeconômicas se faz necessária para entender os processos nosológicos de doenças, que se produzem socialmente, tais como a leptospirose ${ }^{17,18}$.

O Geoprocessamento, por se constituir em um conjunto de técnicas de coleta, tratamento, manipulação e apresentação de dados espaciais, tem contribuído para a implementação de análise sistemática, processual e contínua de ocorrência das doenças e dos riscos à saúde. Dentro das ciências da saúde, o geoprocessamento tem contribuído para a criação de Sistemas de Informação Geográfica (SIG), principalmente para os estudos ecológicos, pois permite a análise de relações espaciais entre as entidades e os eventos biológicos ${ }^{19,20}$.

Historicamente, a transmissão desta doença ocorre em áreas com problemas de infraestrutura sanitária, tais como, ausência de esgotos, acumulo de lixo a céu aberto e inundações nas margens de canais, sendo que estas variáveis aumentam a vulnerabilidade de pessoas com baixa renda per capita, pouca escolaridade e que moram nessas áreas susceptíveis à circulação do patógeno. $\mathrm{O}$ presente trabalho teve como objetivo analisar a distribuição espacial e temporal da leptospirose e sua relação com fatores de risco socioambientais nos bairros Condor, Guamá e Jurunas, em Belém do Pará, no período de 2007 a 2013. Estes bairros foram escolhidos, devido a apresentarem as maiores notificações da doença, no município, ao longo do período de estudo.

\section{Materiais e métodos}

Este estudo transversal, retrospectivo, observacional, descritivo, de base populacional e sem coleta de material biológico foi realizado de acordo com as normas de pesquisa do Conselho Nacional de Saúde ${ }^{21}$. Sendo realizado nos bairros Condor, Guamá e Jurunas, em Belém do Pará, no período de 2007 a 2013, com o total de 241 casos notificados de leptospirose humana, obtidos no Sistema de Informação de Agravos de Notificação (SINAN), da Secretaria de Municipal de Saúde (SESMA). Estes casos foram georreferenciados em relação aos setores censitários pertinentes a cada um dos bairros que compuseram a área de estudo. Tornando-se desta forma estes setores censitários a unidade espacial de análise. 
Os dados relativos às variáveis de indivíduo selecionados foram: gênero, idade, etnia e ocupação. Os dados socioeconômicos associados aos setores censitários, tais como acumulo de resíduos sólidos, presença de esgoto, alagamentos, água encanada, características da habitação e arruamento foram obtidos em processo observacional, que ocorreu junto com o georreferenciamento dos casos. Estas informações foram analisadas a partir da sua ocorrência em dados pontuais e de áreas, tais como a localização da residência dos casos e os setores censitários, enquanto características intrabairros.

Os dados relacionados aos indivíduos e às características socioenconômicas foram analisados estatisticamente com a utilização de proporções e da técnica não paramétrica qui-quadrado, com $\mathrm{p}<0,05$, utilizando os softwares Epi Info 7 e Biostat 5.0. A técnica de Análise Temática da Informação (ATI) foi utilizada para a criação do modelo de interrelacionamento das variáveis e o Software TerraView 4.1.3, para o seu processamento e geração de expressões visuais.

Os mapas epidemiológicos com as análises da distribuição dos casos foram gerados com a utilização de uma imagem do satélite SPOT 5 , de órbita ponto $702 / 353 w$, de 25 de agosto de 2007, disponibilizada pela Secretaria de Estado de Meio Ambiente do Pará (SEMA) e com bases cartográficas na escala 1:250.000, dos bairros estudados com suas divisões em setores censitários, disponibilizada pelo Instituto Brasileiro de Geografia e Estatística ${ }^{18}$. Estas bases cartográficas foram também utilizadas para obter dados de drenagem, localização dos canais a céu aberto e altimetria. Os dados ambientais relativos aos períodos de La Niña e El Niño foram obtidos em relatórios técnicos do Sistema de Proteção da Amazônia (SIPAM) 22 .

A densidade espacial da leptospirose humana e sua delimitação foram obtidas com a utilização das técnicas de estimativa de Krigagem numérica e de Buffer, com raio de 400 metros, que possibilitaram a identificação da extensão da concentração de casos a partir de uma interpolação espacial de dados pontuais, com aplicação para dados de área. A técnica de estimativa de Moran foi utilizada para medir a autocorrelação espacial da localização dos casos contidos em setores censitários com as áreas onde ocorreram os fatores de riscos ambientais e socioeconômicos levantados, devido esta técnica estimar uma autocorrelação direta, indireta ou inexistente entre dados expressos em áreas.

\section{Resultados}

O maior percentual de infecção, ao longo de toda a série de estudo, ocorreu em indivíduos do sexo masculino, $68,88 \%$ (166/241), sendo a razão entre os gêneros de 2:1. Aproximadamente 60,64\% dos casos notificados foram na faixa etária de 15 a 50 anos (163/241), com idade média de 32 e mediana de 28 anos. Os casos com menores de 15 anos compreenderam 16,18\% (39/241). Do ponto de vista da ocupação, 50,21\% (121/241) dos casos declararam-se trabalhadores informais, 16,18\% (39/241) prestadores de serviços, 1,66\% (4/241) realizavam trabalhos técnicos de nível médio e superior e, no restante, 31,95\% (77/241), as informações estavam inexistentes. Com relação à classificação da etnia, foi observado que 57,68\% (139/241) declararam-se pardos, 2,48\% (3/241) brancos e negros e o restante $39,84 \%$ (99/241) eram informações inexistentes. Todos estes resultados mostraram-se significantes em relação aos casos notificados, com p $=0,0001$.

O maior número de casos de leptospirose, em todo o período, foi registrado no bairro do Guamá (144), seguido por Jurunas (79) e Condor (18). A utilização da estimativa de Krigagem numérica mostrou que embora os três bairros sofram influência de canais, a maior concentração da doença nos bairros do Guamá e do Jurunas, ocorreu em áreas que apresentaram as menores cotas altimétricas. Fato este, que favorece o estabelecimento de alagamentos. A associação espacial destas variáveis constituiu fator de risco ambiental para o estabelecimento da doença (Figura 1).

Analisando a tendência geral, dada pela função linear de regressão $\mathrm{y}=-0.2857 \mathrm{x}+12.619$ com coeficiente de correlação $\left(\mathrm{R}^{2}\right)$ de 0,7423 , foi observado um decréscimo da doença nos anos de estudo. Sendo que os bairros Guamá e Jurunas apresentaram comportamento de decréscimo discreto e mediano, respectivamente. Contudo, o bairro da Condor apresentou uma tendência de pequeno aumento no número de casos (Gráfico 1).

Com relação aos fatores de riscos socioeconômicos de transmissão da leptospirose, observados nos setores censitários dos bairros Guamá, Jurunas e Condor, a presença de acúmulo de resíduos sólidos domiciliares ocorreu na ordem de $36,11 \%, 26,58 \%$ e $66,67 \%$; a ausência de esgoto de $27,78 \%, 0,00 \%$ e 11,11\%; ausência de água encanada de 19,44\%, 51,90\% e 11,11\%; habitação de madeira de 29,86\%, 22,78\% e 16,67\% e arruamento não pavimentado de 39,58\%; 22,78\% e $5,56 \%$, respectivamente. Estes indicadores apon- 

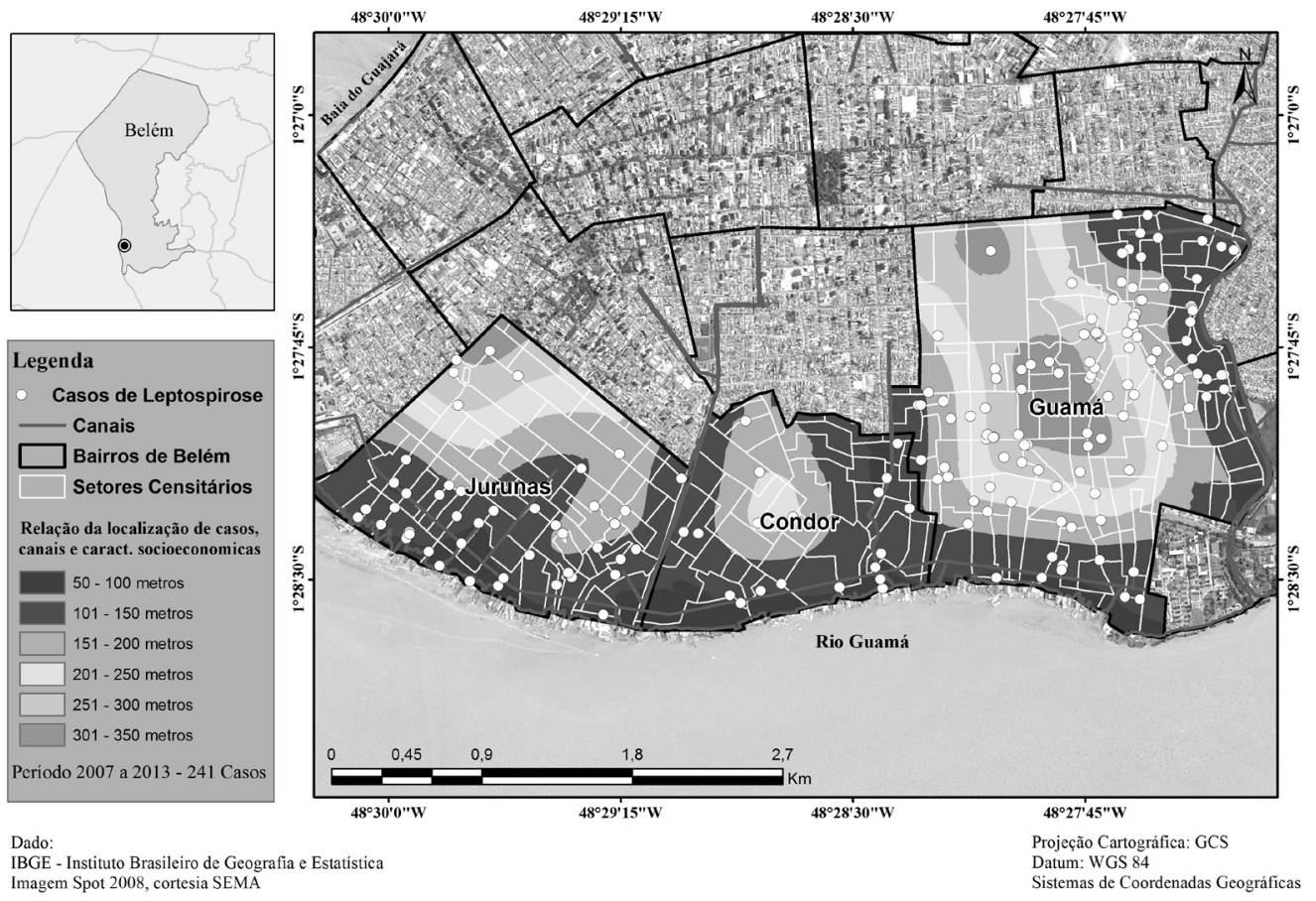

Figura 1. Correlação espacial da Leptospirose e fatores de riscos ambientais na área de estudo e período. 2007 a 2013.

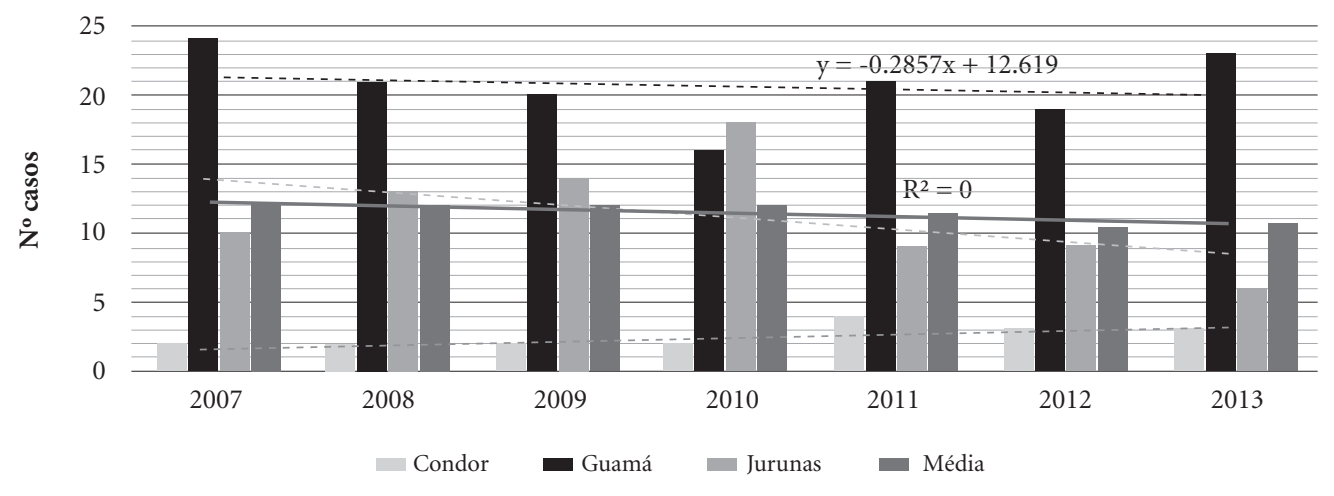

Gráfico 1. Regressão Linear da incidência da Leptospirose na área de estudo, no período de 2007 a 2013.

tam para a fragilidade socioeconômica da área de estudo, que numa perspectiva epidemiológica se constitui de uma área favorável para o estabelecimento e manutenção da doença (Tabela 1).

A relação espacial entre os setores censitários, na área de influencia dos canais a céu aberto com notificações de casos e fatores de riscos socioeconômicos, delimitado pela técnica de Buffer, mostrou que a maior concentração da doença ocorreu em áreas onde existe ausência de coleta de resíduos sólidos domiciliares (26\%), esgoto (22\%) e água encanada (38\%). Nestes setores também 
foi observado: habitações em madeira (37\%), arruamento não pavimentado (20\%) e alagamento de rua (65\%). A partir da utilização da técnica de Moran foi possível observar que houve uma autocorrelação espacial direta entre estas variáveis, com $\mathrm{p}=0,01543$ (Figura 2).

Os indicadores operacionais de vigilância mostraram que o ambiente domiciliar representou o principal local provável de infecção, com aproximadamente $27,8 \%$, seguido pelo local de trabalho com 4,15\%, entretanto, em $66,88 \%$ (161/241) das fichas de investigação esta informação encontrava-se ignorada ou em branco. Não houve diferença estatística entre período do ano e ambientes prováveis de infecção.

Com relação ao diagnóstico, 83,82\% (202/241) dos casos de leptospirose foram obtidos laboratorialmente. Sendo que dos 39 casos

Tabela 1. Fatores de riscos socioeconômicos, na área de estudo. Belém-Pará. 2007-2013.

\begin{tabular}{lccccc}
\hline \multirow{2}{*}{ Bairro } & \multicolumn{5}{c}{ Fatores de Risco (\%) } \\
\cline { 2 - 6 } & $\begin{array}{c}\text { Resíduos Sólidos } \\
\text { Domiciliares }\end{array}$ & $\begin{array}{c}\text { Ausência } \\
\text { de esgoto }\end{array}$ & $\begin{array}{c}\text { Ausência de água } \\
\text { encanada }\end{array}$ & $\begin{array}{c}\text { Habitação de } \\
\text { madeira }\end{array}$ & $\begin{array}{c}\text { Arruamento não } \\
\text { pavimentado }\end{array}$ \\
\hline Guamá & 36,11 & 27,78 & 19,44 & 29,86 & 39,58 \\
Jurunas & 26,58 & 0 & 51,9 & 22,78 & 22,78 \\
Condor & 66,67 & 11,11 & 11,11 & 16,67 & 5,56 \\
\hline
\end{tabular}

Fonte: EpiGeo/DSCM/CCBSUEPA.

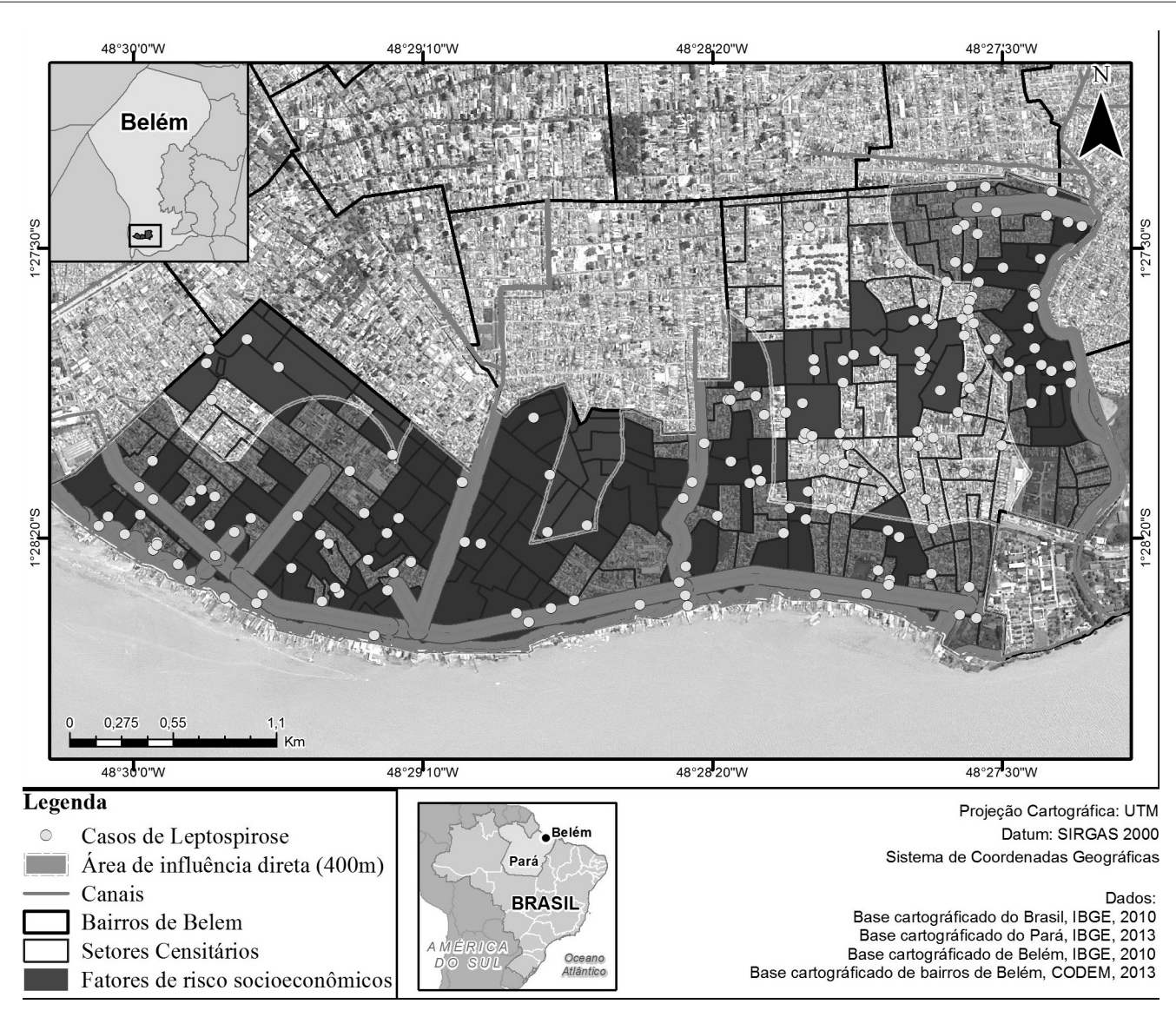

Figura 2. Correlação da área de influencia dos canais, com a ocorrência da Leptospirose e fatores de risco socioeconômico, na área de estudo. Período 2007 a 2013. 
restantes 14,54\% (35/241) foram confirmados por critérios clínicos epidemiológicos e apenas 4 constam sem informação. Aproximadamente $67,22 \%(162 / 241)$ dos casos tiveram atendimento hospitalar e $28,63 \%(69 / 241)$ não, contudo $4,15 \%$ (10/241) constaram sem informação. Com relação à evolução dos casos 67,98\% (159/241) obtiveram cura, sendo que em 7,05\% (17/241) dos óbitos por leptospirose 70,59\% (12/17) estavam na faixa etária de 15 a 50 anos, grupo de pessoas em idade produtiva, o que demonstra ter esta doença um custo social relativamente alto, em comparação com outras infecções de etiologia bacteriana, bem como representa custos adicionais ao sistema de saúde.

\section{Discussão}

A leptospirose apresentou um comportamento endêmico e sem surtos de casos nos três bairros e no período estudado, embora o número de notificações tenha sido alto em relação aos demais bairros do município de Belém. Esta situação pode estar relacionada à dependência espacial observada entre as variáveis ambientais, socioeconômicas e epidemiológicas. Entretanto, estudos sistemáticos e contínuos são necessários para avaliar estas causalidades.

Neste trabalho foi observado que o sexo masculino representou aproximadamente $68,88 \%$ das notificações. Este fato pode estar relacionado ao maior grau de exposição que os homens possuem em relação aos fatores de risco por ficarem mais tempo fora do domicílio, por desenvolverem atividades ocupacionais insalubres em trabalhos informais, de baixa qualificação nas ruas ou feiras livres, com situações ou práticas que facilitam a infecção ${ }^{15,23}$.

A faixa etária mais acometida foi a de 15 a 50 anos. Assim como para o gênero, a leptospirose não apresenta tendência à determinada faixa etária, porém o fato da maioria da população economicamente ativa estar contida nesta faixa etária, sugere uma relação da mesma com a realização de trabalhos em condições insalubres e o impacto econômico desta doença ${ }^{15,24}$.

Foi observado também que a infecção ocorreu de forma expressiva em menores de 15 anos, sugerindo ambiente domiciliar e peridomiciliar como possível área de exposição a fatores de risco, devido à prática de brincadeiras ou esportes em contato com lama ou água empossada ${ }^{15}$. Foi observado um alto número de notificações sem a informação sobre a etnia $(39,84 \%)$, consideran- do que esta doença é produzida socialmente, a ausência desta informação dificulta a construção de um indicador social para a doença, pois nas áreas onde ocorreram os maiores números de casos moram populações afro-descentes e pardos, que historicamente estão associados à fragilidade social, que se constitui como um fator de risco de adoecimento para populações humanas ${ }^{9,25}$.

A maior notificação dos casos nos primeiros semestres dos anos de estudo pode estar relacionada com a ocorrência de fenômenos climáticos como o El Niño, cuja principal característica é a incidência de alta pluviosidade, que associada às baixas cotas altimétricas observadas nas áreas próximas aos canais a céu aberto presentes na área de estudo, ocasionaram quadros de enchentes, que são fatores de risco de transmissão da doença ${ }^{26-28}$.

Os setores censitários onde foram observadas as maiores relações entre as variáveis ambientais, socioeconômicas e epidemiológicas, nas áreas de estudo, são áreas baixas de várzea, próximas a canais de águas pluviais e sujeitas às inundações sazonais, nos períodos de maré alta. Estas características associadas à ocupação territorial desordenada, resultante do intenso processo de urbanização, com aglomeração de pessoas em áreas sem saneamento básico, água potável, destino adequado dos resíduos sólidos e com esgotos a céu aberto possibilitou a concentração de casos da doença, ao longo do período de estudo ${ }^{29,30}$.

Assim sendo, foi possível observar que a produção do espaço urbano desordenado constituiu uma situação de vulnerabilidade com fatores de risco de adoecimento dos moradores, por leptospirose. A associação destas precárias características socioeconômicas com a maior densidade de casos mostra também, que estas áreas apresentam alta fragilidade ambiental com impacto na epidemiologia da doença, devido à observação da dependência espacial dos fatores de risco ${ }^{10,15,31}$.

O fato do diagnóstico ter sido confirmado por métodos laboratoriais em $82 \%$ dos casos e ter ocorrido $67,22 \%$ de atendimento hospitalar, demonstra satisfatório acesso aos serviços de saúde ${ }^{23,25,28}$. Foi observada alta letalidade $70,59 \%$ (12/17), em pessoas na idade produtiva, taxa bem superior ao apresentado na literatura para as formas graves da doença, que varia de 5 a $40 \%$, podendo esta letalidade estar relacionada aos sorovares infectantes, à gravidade das formas clínicas, à deficiência de diagnóstico precoce, ao tratamento e, dentre outros fatores, à faixa etária do paciente, apontando para uma falha no sistema de vigilância epidemiológica e ambiental da 
doença ${ }^{6,32,33}$. Esses fatores demonstram que esta nosologia possui um custo social relativamente alto, em comparação com outras infecções de etiologia bacteriana, bem como representa custos adicionais ao sistema de saúde, mostrando desta forma a necessidade de realização de ações contínuas de promoção da saúde e de vigilância deste agravo.

A utilização de técnicas de análise espacial e o geoprocessamento dos casos de leptospirose notificados, possibilitou observar uma concentração nas áreas próximas aos canais a céu aberto, tendo sido satisfatória para gerar análise das relações entre as variáveis ambientais, socioeconômicas e epidemiológicas, observadas no âmbito deste estudo ${ }^{34,35}$.

\section{Conclusão}

Neste trabalho, foi observado que a leptospirose ocorreu em função da relação entre fatores de riscos associados a variáveis ambientais, geográficas e baixas condições socioeconômicas. Para o entendimento das relações entre as variáveis anteriormente citadas, foram utilizadas geotecnologias que consideraram o tempo e o espaço no estabelecimento da doença. Os dados gerados podem ser utilizados para apoiar processos de tomadas de decisão.

A análise espaço-temporal dos casos de leptospirose registrados pelo SINAN da SESMA, considerando as relações intrabairros na área de estudo, possibilitou o conhecimento da distribuição geográfica da doença, ao identificar padrões não homogêneos, com concentração nas áreas próximas aos canais a céu aberto do Tucunduba e do Bernardo Sayão, principalmente no bairro do Guamá, que, além da problemática dos canais a céu aberto, tem alta densidade demográfica, com o maior número de pessoas expostas, não apenas devido às questões ambientais, mas, sobretudo às questões socioeconômicas, sendo desta forma o empobrecimento das populações humanas o maior fator de risco observado neste estudo.

A geração dos mapas epidemiológicos foi capaz de expressar visualmente as correlações dos determinantes da ocorrência de leptospirose, por meio das técnicas de Buffer, estimativa de Krigagem numérica e Moran, que se constituíram desta forma como ferramentas tecnológicas importantes para a percepção da iniquidade em saúde observada.

O estudo das relações dos fatores de risco ambientais e socioeconômicos com a ocorrência da doença mostrou que o tempo e o espaço geográfico se constituíram de critérios para avaliar esta relação do ponto de vista intrabairros, devido às constantes alterações que ocorrem do ponto de vista demográfico. Este fato ratificou a necessidade da continuidade de estudos da leptospirose e seus determinantes socioambientais, no sentido da sua desagregação em escalas locais, para que seja possível estabelecer medidas para a mitigação da doença nos seus diversos aspectos.

As variações climáticas e seus extremos não são controláveis pela ação humana, por isso o estudo das suas consequências sobre as condições de saúde das populações também se constituem de um desafio processual, sistemático e contínuo.

Por fim, consideramos que medidas voltadas para a melhoria do saneamento básico, tais como coleta adequada de resíduos sólidos, limpeza dos canais a céu aberto e bueiros existentes na área de estudo evitariam inundações e alagamentos, ou seja, a execução de medidas viáveis voltadas para o acompanhamento e a mitigação deste agravo enquanto problema de saúde pública. 


\section{Colaboradores}

NV Gonçalves trabalhou na concepção, redação e aprovação do artigo; EN Araújo trabalhou na concepção e o delineamento dos dados; AS Sousa Júnior, WMM Pereira, CSC Miranda, MWS Matos e PSS Campos trabalharam na concepção, delineamento e interpretação dos dados, redação e aprovação do artigo; VRCM Palácios participou da aprovação da versão a ser pública.

\section{Referências}

1. Marinho M. Fatores epidemiológicos, fisiopatológicos e imunopatogênicos. Veterinária e Zootecnia 2008; 15(3):428-434.

2. Brasil. Ministério da Saúde (MS). Secretaria de Vigilância em Saúde. Departamento de Vigilância das Doenças Transmissíveis. Leptospirose: diagnóstico e manejo clínico. Brasília: MS; 2014.

3. Veronesi R, Focaccia R. Tratado de Infectologia. $3^{\mathrm{a}}$ ed. São Paulo: Atheneu; 2005.

4. Pereira CAR. Custo social da leptospirose no Brasil e o efeito de chuvas extremas em Nova Friburgo para o incremento de casos da doença. 2013 [dissertação]. Rio de Janeiro. Escola Nacional de Saúde Pública Sergio Arouca, 2013.

5. Buzzar MR. Perfil epidemiológico da leptospirose no estado de São Paulo no período de 2007 a 2009. In: Anais da $1^{a}$ Conferência Internacional em Epidemiologia; 2010; São Paulo.

6. Souza VMM, Arsky MLNS, Castro APB, Araujo WN. Anos potenciais de vida perdidos e custos hospitalares da leptospirose no Brasil. Rev Saude Publica 2011; 45(6):1001-1008.

7. Oliveira DSC. Desigualdades intraurbanas de leptospirose no Recife [tese]. Recife. Centro de Pesquisas Aggeu Magalhães; 2009.

8. Pará. Secretaria Municipal de Coordenação Geral do Planejamento e Gestão (CEGEP). Anuário Estatístico do Município de Belém. Belém: CEGEP; 2012.

9. Reis RB, Ribeiro GS, Felzemburgh RDM, Santana SS, Mohr S, Melendez AXT, Queiroz A, Santos AC, Ravines RR, Tassinari WS, Carvalho MS, Reis MG, Ko AI. Impact of environment and social gradient on leptospira infection in urban slums. PLoS Negl Trop Dis 2(4):e228, april 23, 2008.

10. Oliveira TVS, Marinho, DP, Neto CC, Kligerman DC. Variáveis climáticas, condições de vida e saúde da população: a leptospirose no Município do Rio de Janeiro de 1996 a 2009. Cien Saude Colet 2012; 17(6):15691576.

11. Lira VA, Sá LACM. Aplicação de tecnologias de geoinformação para espacializar os casos de leptospirose. In: Anais $3^{o}$ Simpósio Brasileiro de Ciências Geodésicas e Tecnologias da Geoinformação, 2010; Recife. A263.

12. Soares TSM. Análise espacial e sazonal da leptospirose no município de São Paulo, SP, 1998 a 2006. Rev Saude Publica 2010; 44(2):283-291.

13. Melo CB, Reis RB, Ko AI, Barreto CMN, Lima AP, Silva AM. Espacialização da leptospirose em Aracaju, Estado de Sergipe, no período de 2001 a 2007. Rev Soc Bras Med Trop 2011; 44(4):475-480.

14. Pelissari DM, Elkhoury-Maia ANS, Arsky MLNS, Nunes ML. Revisão sistemática dos fatores associados à leptospirose no Brasil, 2000-2009. Epidemiol Serv Saude 2011; 20(4):565-574. 
15. Vasconcelos CH, Fonseca FR, Lise MLZ, Arsky MLNS. Fatores ambientais e socioeconômicos relacionados à distribuição de casos de leptospirose no Estado de Pernambuco, Brasil, 2001-2009. Cad. saúde colet 2012; 20(1):49-56.

16. Bernardi I. Leptospirose e saneamento básico [monografia]. Florianópolis: Universidade Federal de Santa Catarina; 2012.

17. Instituto Brasileiro de Geografia e Estatística (IBGE). Base Cartográfica Contínua do Brasil na escala 1:250.000 (versão 1.0). [acessado $2014 \mathrm{fev}$ 1]. Disponível em: http://downloads.ibge.gov.br/downloads_geociencias. htm

18. Instituto Brasileiro de Geografia e Estatística (IBGE). Censo demográfico 2010: resultados do universo relativo às características da população e dos domicílios (bairros de Belém). Rio de Janeiro: IBGE; 2012.

19. Pereira SHF. Uso do Geoprocessamento na Análise Espacial da Tuberculose na Área Urbana de Viçosa - MG. [Monografia] Viçosa, MG: Universidade de Viçosa, 2006.

20. Barcellos C, Ramalho WM, Gracie R, Magalhães MAFM, Fontes MP, Skaba D. Georreferenciamento de dados de saúde na escala submunicipal: algumas experiências no Brasil. Epidemiol Serv Saude; 2008 17(1):5970.

21. Brasil. Ministério da Saúde (MS). Resolução no 466 de 12 de dezembro de 2012. Dispõe sobre diretrizes e normas regulamentadoras de pesquisa envolvendo seres humanos e atualiza a resolução 196. Diário Oficial de União 2013; 13 jun.

22. Brasil. Ministério da Defesa (MD). Sistema de Proteção da Amazônia. Centro Regional de Belém/PA. Programa de Monitoramento de Áreas Especiais 2009/2012. Brasília: MD; 2012.

23. Sampaio GP, Wanderley MR, Casseb GB, Negreiros MAMP. Descrição epidemiológica dos casos de leptospirose em hospital terciário de Rio Branco. Rev Bras Clin Med; 2011 9(5):338-343.

24. Jansen A, Luge E, Guerra B, Wittschen P, Gruber AD, Loddenkemper TS, Lierz M, Ehlert D, Appel B, Stark K, Nockler K. Leptospirosis in Urban Wild Boards, Berlim, Germany. Em Infect Dis 2007; 13(5):739-742.

25. Lima RJS, Abreu EMN, Ramos FLP, Santos RD, Santos DD, Santos FAA, Matos LM, Saraiva JMB, Costa ARF. Análise da distribuição espaço-temporal da leptospirose humana em Belém, Estado do Pará, Brasil. Rev Pan -Amaz Saude 2012; 3(2):33-34.

26. Marengo JA. Mudanças climáticas globais e seus efeitos sobre a biodiversidade: caracterização do clima atual e definição das alterações climáticas para o território brasileiro ao longo do século XXI. Brasília: MMA, 2006.
27. Oliveira TVS. Fatores socioambientais associados a eventos hidrometeorológicos extremos na incidência de leptospirose no município do Rio de Janeiro, 1997 a 2009: um estudo de caso [tese] Rio de Janeiro: Escola Nacional de Saúde Pública; 2013.

28. Souza MHF, Aarão Junior RNN, Costa ACL. Leptospirose humana: uma análise de sua manifestação no município de Belém/PA. In: Anais $16^{\circ}$ Congresso Brasileiro de Meteorologia; 2010.

29. Sarkar U, Nascimento SF, Barbosa R, Martins R, Nuevo H, Kalafanos I, Grustein I, Flannery B, Dias J, Riley LW, Galvão Reis M, Ko IA. Population-based case-control investigation of risk factors for leptospirosis during an urban epidemic. Am J Trop Med Hyg 2002; 66(5):605610.

30. Schmitz CAA. Cartografia regional da leptospirose: dinâmica espaço-temporal da patologia na $4^{a}$ Coordenadoria Regional de Saúde [dissertação]. Santa Maria: Universidade Federal de Santa Maria; 2010.

31. Guimaraes RM, Cruz OG, Parreira VG, Mazoto ML, Vieira JD, Asmus CI. Temporal analysis of the relationship between leptospirosis and the occurrence of flooding due to rainfall in the city of Rio de Janeiro, Brazil, 2007-2012. Cien Saude Colet 2014; 19(9):3683-3692.

32. Zunino ME, Pizarro PR. Leptospirosis: Puesta al día. Rev. chil. infectol. 2007; 24(3):220-226.

33. Paploski IAD. História natural da leptospirose urbana: influência do sexo e da idade no risco de infecção, progressão clínica da doença e óbito [dissertação]. Salvador: Fundação Oswaldo Cruz; 2013.

34. Rocha AMM. Formulação de um Modelo de Análise Epidemiológica usando Raciocínio Baseado em Casos e Geoprocessamento [dissertação]. São Paulo: Pontifícia Universidade Católica de São Paulo; 2012.

35. Tassinari WS, Pellegrini DCP, Sabroza PC, Carvalho MS. Distribuição espacial da leptospirose no Município do Rio de Janeiro, Brasil, ao longo dos anos de 1996-1999. Cad Saude Publica 2014; 20(6):1721-1729.

Artigo apresentado em 22/12/2015

Aprovado em 07/06/2016

Versão final apresentada em 09/06/2016 